\title{
Thickener experiences at Langer Heinrich Mine
}

\author{
M. Cooks Langer Heinrich Uranium (Pty) Ltd, Namibia \\ D. Mostert Langer Heinrich Uranium (Pty) Ltd, Namibia
}

L. Coetzee Langer Heinrich Uranium (Pty) Ltd, Namibia

D.J. van Schalkwyk Langer Heinrich Uranium (Pty) Ltd, Namibia

\section{Abstract}

Langer Heinrich Mine (LHM) reports on the operational experiences of thickeners supplied by several vendors. Modifications that were made to mitigate challenges presented by the thickener operation are discussed.

The in-house modifications to the Lightnin ${ }^{\circledR}$ thickener improved capacity, reliability and performance, and the modifications of which, are ongoing. The ANDRITZ Delkor (Pty) Ltd thickener modifications were successful and the thickeners are performing to specification. Indications are that the Roymec Technologies (Pty) Ltd thickeners will perform to specification. The Magra Ultrasep 2000 High Performance Thickener is still in the commissioning phase at the time of writing.

\section{Introduction}

Langer Heinrich Mine is part of the Paladin Energy Group. The mine is located in Namibia some $80 \mathrm{~km}$ east of the town of Swakopmund. The orebody is located in the Namib-Naukluft National Park in the Namib Desert. This location presents unique challenges.

The project is being developed in stages. Stage 1 was commissioned in 2006, Stage 2 followed in 2009, and Stage 3 is currently in the commissioning and ramp-up phase.

Nine $25 \mathrm{~m}$ Lightnin thickeners and clarifiers were installed as part of Stage 1 . The thickener functions were the following: one pre-leach thickener, six CCD thickeners, one clarifier, and one 'vanadium' thickener. The 'vanadium' thickener was converted to a clarifier during the ramp-up of Stage 1.

Stage 2 development required an additional four $35 \mathrm{~m}$ thickeners. The $25 \mathrm{~m}$ Lightnin pre-leach thickener was replaced by a $35 \mathrm{~m}$ thickener, a $35 \mathrm{~m}$ thickener was installed as the CCD 1 thickener and two $35 \mathrm{~m}$ thickeners were installed as CCD 5 and CCD 6. These $35 \mathrm{~m}$ thickeners were supplied by ANDRITZ Delkor (Pty) Ltd. The Lightnin thickener configuration was changed to run as three sets of two parallel thickeners and performed duty as CCD 2 A \& B, CCD 3 A \& B and CCD 4 A \& B. The $25 \mathrm{~m}$ Lightnin pre-leach thickener functioned as a standby pre-leach unit.

Stage 3 upgrade required an additional two $35 \mathrm{~m}$ CCD thickeners; CCD 4 and CCD 7. These $35 \mathrm{~m}$ units were supplied by Roymec Technologies (Pty) Ltd. This necessitated a change in configuration of the Lightnin CCD thickeners. The Stage 3 configuration is comprised of two sets of three parallel thickeners; CCD 2 A, B \& C and CCD 3 A, B \& C.

The chosen tailings deposition for the Stage 3 upgrade is a paste system comprising of a $12 \mathrm{~m}$ Magra Ultrasep 2000 High Performance Thickener, supplied by Magra Process Engineering (MPE), as the paste thickener, the pumping system designed by Paterson \& Cooke (P\&C) and a tailings storage facility (TSF) designed by Metago Environmental Engineers.

A fourth stage expansion is currently in the bankable feasibility study (BFS) stage. 
The continuous expansion and upgrading of LHM caused significant changes in the duty of the thickeners. The increased duty comparison is given in Table 1.

Table 1 The different scenarios for the $25 \mathrm{~m}$ Lightnin pre-leach thickener

\begin{tabular}{lcccc}
\hline Description & Stage 1 & Stage 2 & Stage 3 & Unit \\
\hline Thickener diameter & 25 & 25 & 25 & $\mathrm{~m}$ \\
Solids feed & 163 & 236 & 304 & $\mathrm{t} / \mathrm{hr}$ \\
Volume feed & 1,440 & 2,000 & 2,686 & $\mathrm{~m}^{3} / \mathrm{hr}$ \\
Feed concentration & 10.29 & 10.70 & 10.29 & $\%$ \\
Feed slurry sg & 1.10 & 1.10 & 1.10 & \\
Solids flux rate & 0.33 & 0.48 & 0.62 & $\mathrm{t} / \mathrm{m}^{2} / \mathrm{hr}$ \\
Rise rate & 3.59 & 5.20 & 6.70 & $\mathrm{~m} / \mathrm{hr}$ \\
Underflow concentration & 46.8 & 42.7 & 42.7 & $\%$ \\
Underflow sg & 1.45 & 1.40 & 1.40 & \\
Underflow flow rate & 240 & 395 & 508 & $\mathrm{~m}^{3} / \mathrm{hr}$ \\
\hline
\end{tabular}

This change in duty and the availability of the $25 \mathrm{~m}$ Lightnin pre-leach thickener provided the opportunity to make changes and upgrades to the thickener and the thickener control without influencing the production significantly. The goal of the $25 \mathrm{~m}$ Lightnin pre-leach thickener design changes was to increase the thickener's operational capacity to a full pre-leach standby unit. The standby unit had to be capable of handling Stage 2 tonnages reliably. A stretched goal of Stage 3 tonnages was set.

This paper will focus mainly on the upgrading of the pre-leach thickener with brief discussions of the ANDRITZ Delkor thickener changes and commissioning experiences of the Roymec thickeners and Magra UltraSep thickener.

\section{$2 \quad$ Changes and methodology}

\section{1 Lightnin thickener upgrade}

The thickener upgrading was done in steps and each step tested before continuing to the next step. The first upgrading step consisted of feedwell modifications and the addition of pickets to the rake. In parallel with the thickener modifications, the thickener peripherals were upgraded to handle the increased duty. The second step was aimed at improving the instrumentation and control of the thickener. Instrumentation to monitor the thickener inventory at different levels was installed. The third step was the development of a fully automatic control philosophy and lastly, modifications to ensure continuous and sufficient supply of thickened material to the underflow pumps and a step upgrade of the underflow pumps.

\section{1. 1 First upgrading step \\ 2.1.1.1 Picket addition}

The pre-leach thickener was prone to high torque conditions and bogging. It was therefore with some concern that the addition of pickets was approached. However, this addition was seen as unavoidable if the solids flux was to increase without significant loss of underflow density.

Figure 1 shows the pickets as installed. The pickets were spaced at intervals such that each picket would service similar projected surface area. Three picket diameters were selected with the larger diameter pickets installed to the centre of the thickener and the smaller diameter pickets closer to the tank wall. To 
mitigate some of the drag created by the picket addition, a plate was attached on the 'downstream' side of each picket and angled such that the diameter of the picket was covered.

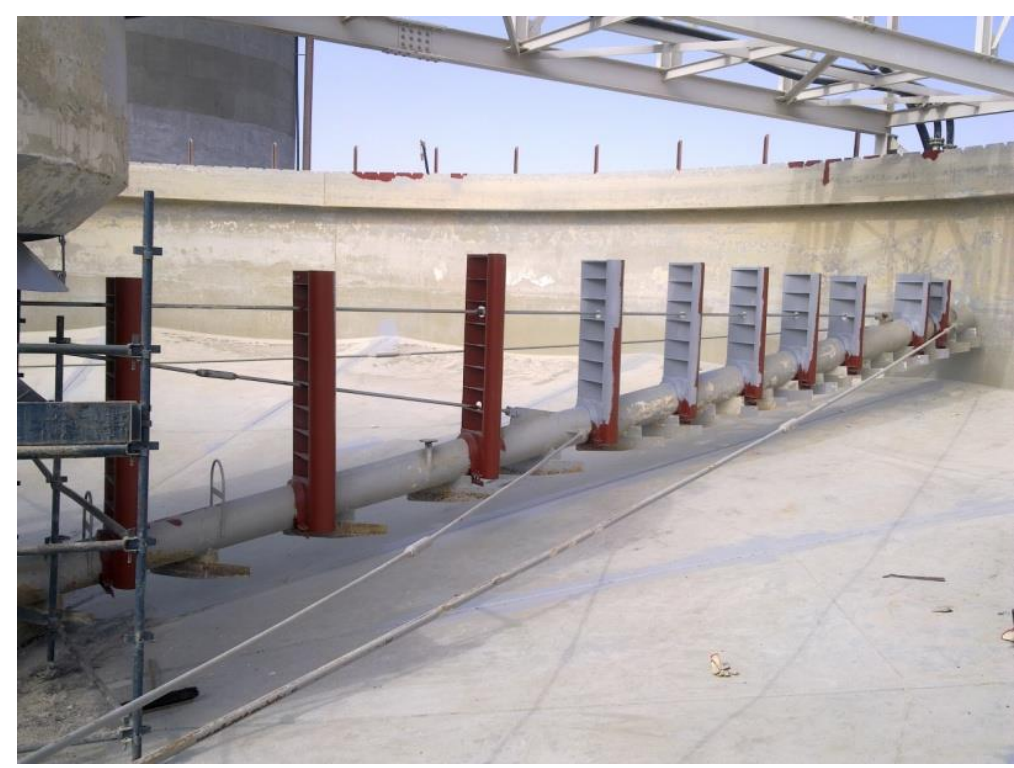

Figure 1 Picket installed in the $25 \mathrm{~m}$ thickener

\subsubsection{Feedwe// modification}

The Lightnin feedwell drawing is shown in Figure 2. The Lightnin feedwell design consists of two concentric rings with the feed reporting tangentially to the inner ring. The inner ring is slotted to allow the slurry to flow to the outer ring. A small cone is fixed onto the rake drive shaft below the feedwell. This cone was considered too small and too far below the feedwell to have any significant effect on the feedwell performance.

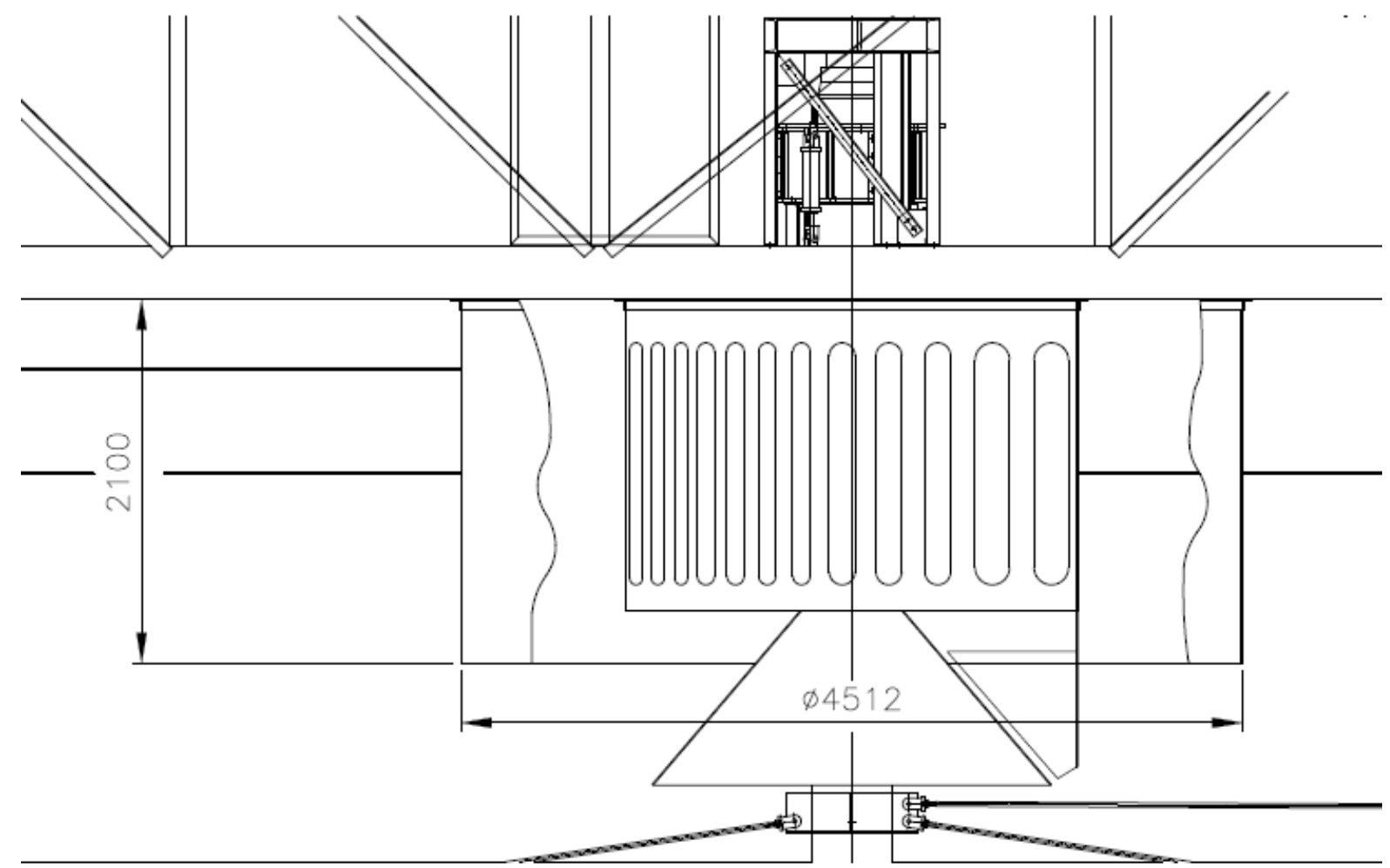

Figure 2 A drawing of the Lightnin feedwell 
It was decided to change the feedwell to a closed feedwell design with a separate deflector cone for each of the feedwell rings. Figures 3 and 4 show the installed deflector cones. The flocculant addition was modified to a four point addition with one dosing point at the feed launder entry to the feedwell, one dosing point in the inner ring away from the feed launder and two dosing points in the outer feedwell ring.

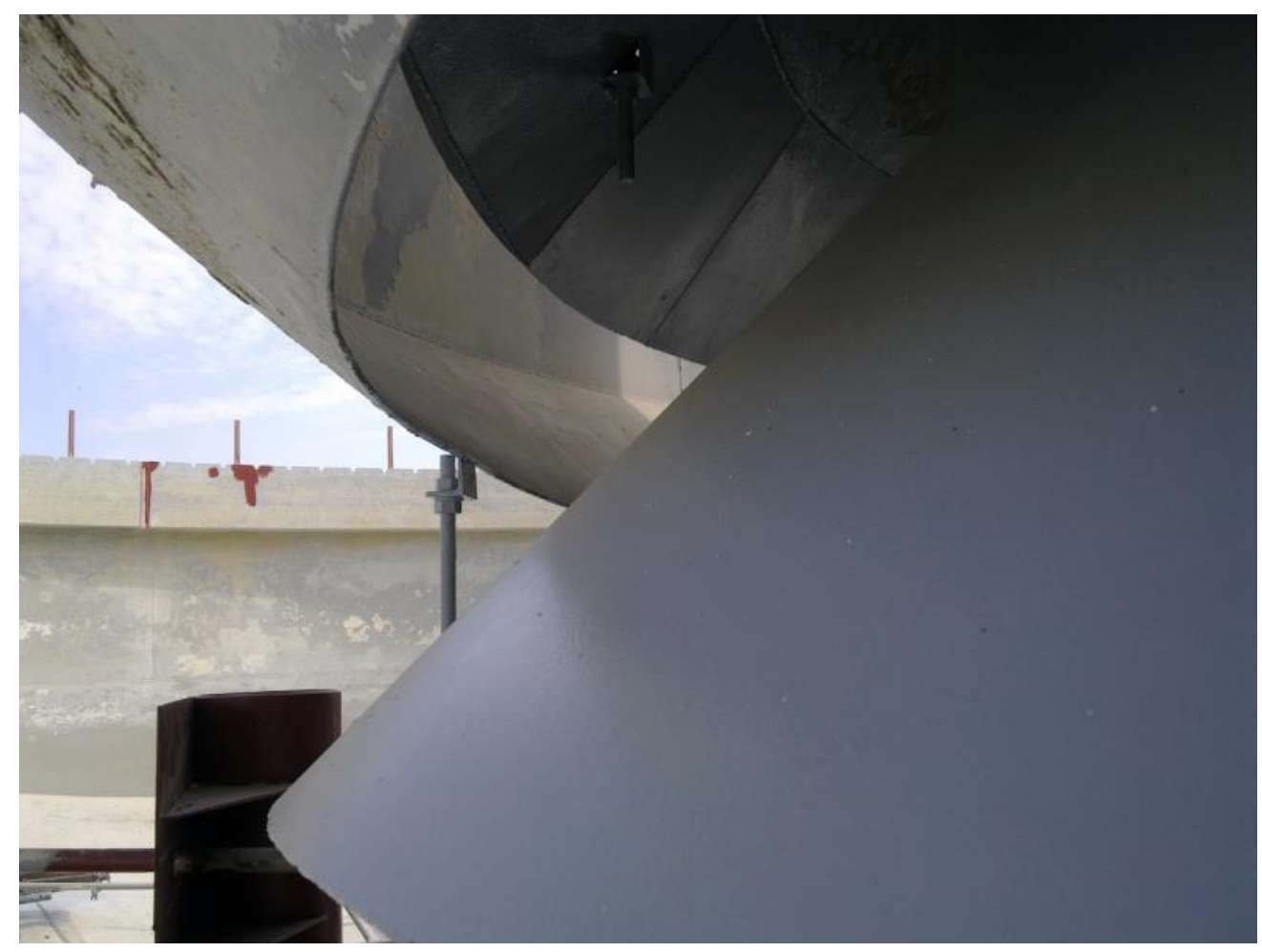

Figure 3 The feedwell design was changed to that of a closed feedwell

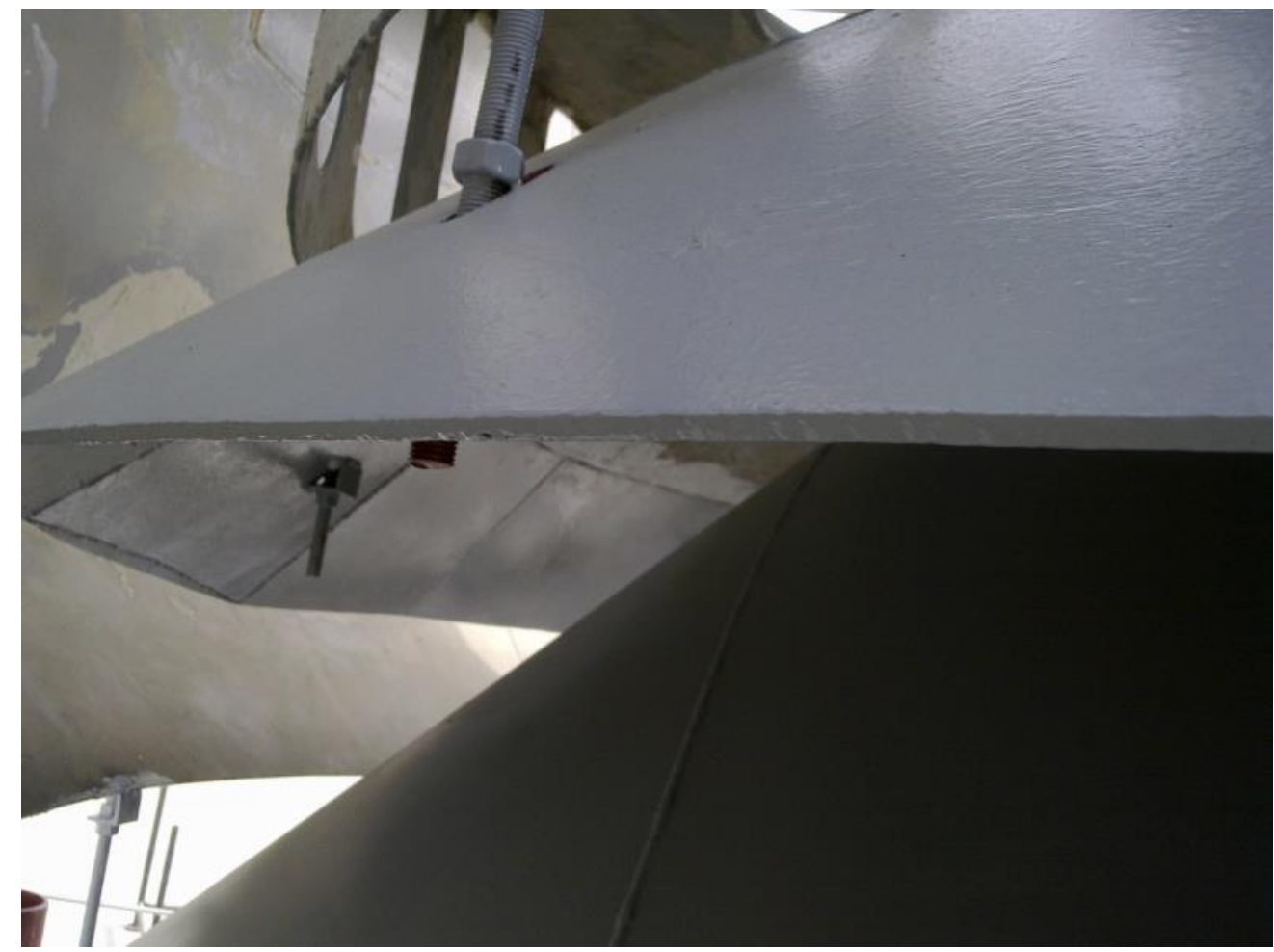

Figure 4 The top deflector cone limits the downward flow of slurry out of the inner feedwell 


\subsubsection{Peripheral upgrading}

Modification of the header tank and the overflow launder discharging to the overflow water tank was required. The header tank side wall height was doubled to allow for additional volume and head. This modification proved to be inadequate because of excessive splashing over the sides and overflowing under mild upset conditions. The connecting launder was increased in size to allow for the increased volume and to reduce restriction of flow to the overflow tank.

The water pumps were upgraded to be capable of handling the Stage 2 volumes. The pipe size was not increased, but would require replacement if the thickener modifications proved to increase the thickener capacity to Stage 3 requirements.

The underflow pumps were upgraded to be capable of handling the increased volumes. The underflow piping was replaced with larger diameter piping.

\subsubsection{Second step upgrade}

During this upgrade, the instrumentation was installed to monitor the thickener inventory at different levels. This close monitoring of the thickener inventory is required because of the thickener tank design criteria for density as indicated in Figure 5.

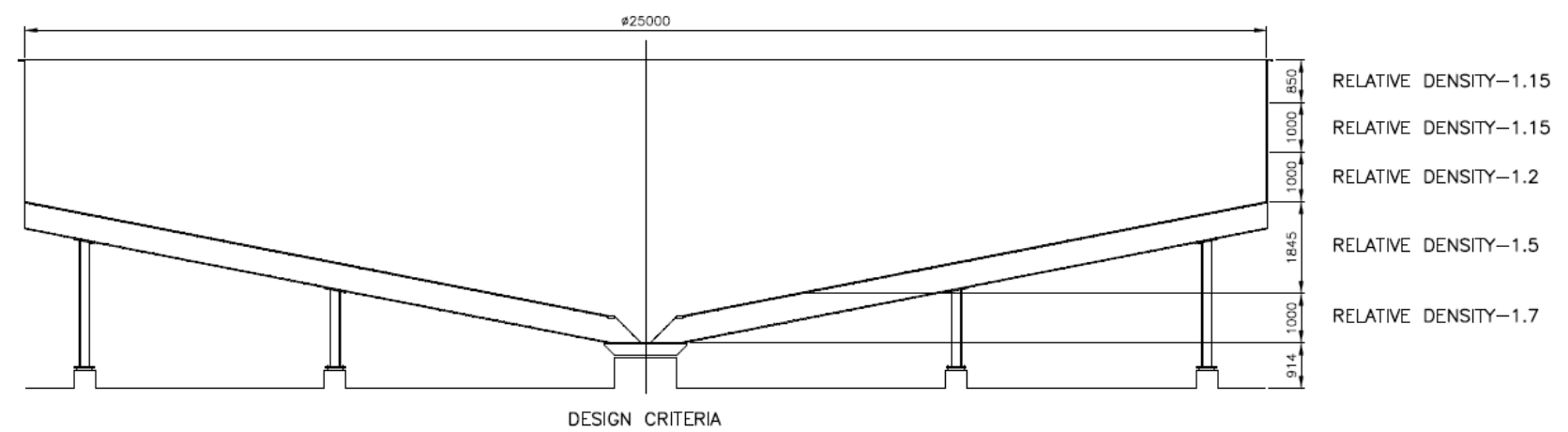

Figure 5 The Lightnin thickener tank design criteria

Pressure sensors capable of measuring the change in pressure as the density of the slurry changes were sourced from Endress+Hauser. The average bed density between two points can be calculated from the differential pressure over that section.

\subsubsection{Third step upgrade}

A fully automated thickener control philosophy was developed. The flocculant requirement at any given time is based on a calculated solids feed rate with the final adjustment based on the thickener inventory distribution. Figure 6 is the screen display for the thickener monitoring and control. The stoppage of the flocculant dosing pump when the thickener bed reaches a predetermined level and density was incorporated as a safety feature. 


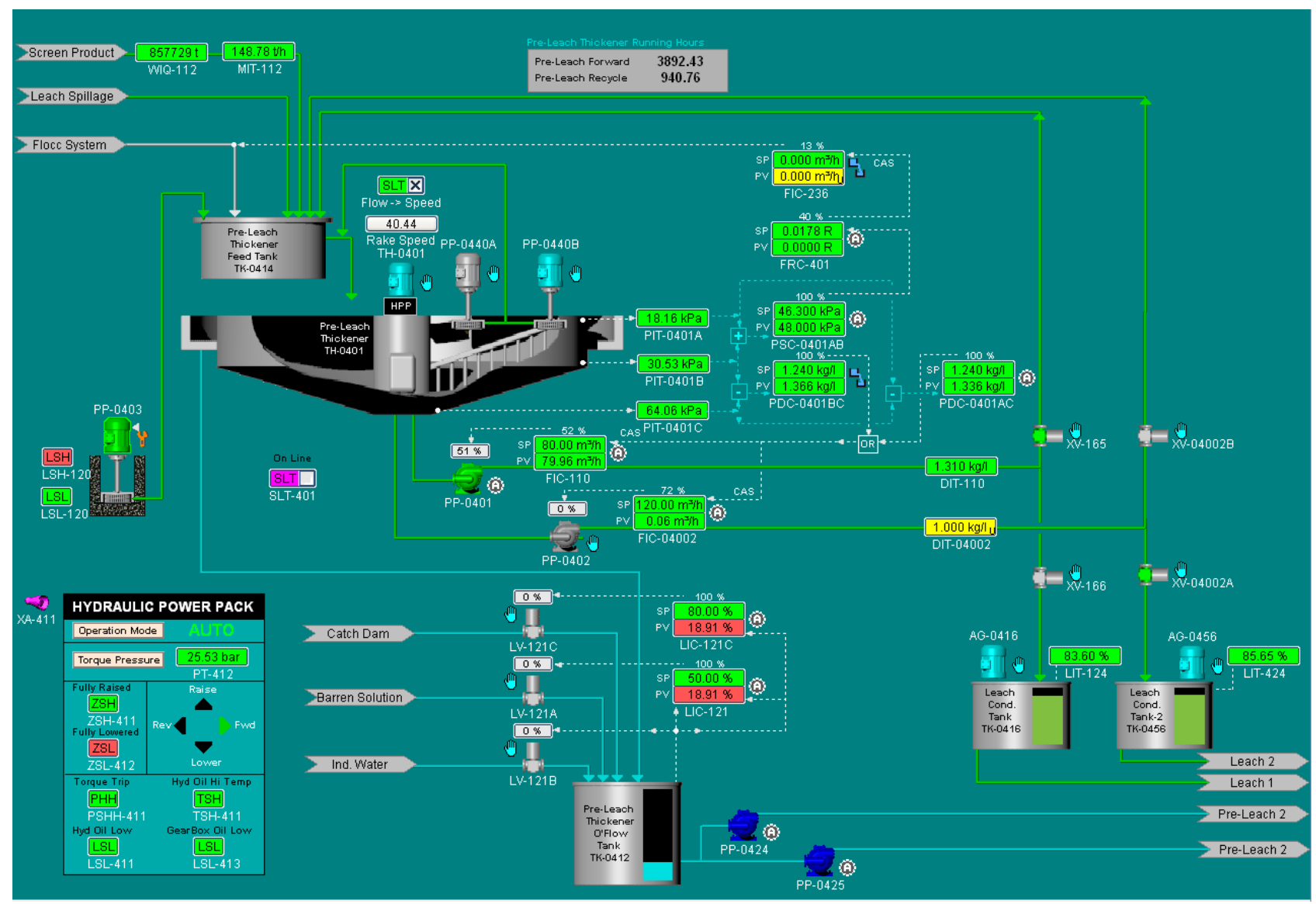

Figure 6 The SCADA control screen for pre-leach one thickener

\subsubsection{Fourth upgrading step}

The thickener underflow density is directly related to the differential pressure over the thickener cone. A comparison of the calculated average thickener cone bed density, to the measured underflow density, gives an indication of the rake efficiency. The pumped thickener underflow specific gravity is expected to be higher than the calculated bed density in the cone. A lower pumped underflow specific gravity is an indication that low density material is reporting to the underflow pump. The thickener rake should ensure plug flow through the thickener and prevent preferential flow.

The rake blades as installed by the vendor can be seen in Figure 1 . The measured slurry density pumped out of the thickener is more often than not lower than the calculated density of the slurry in the cone section of the thickener, therefore rake blades were deemed to be inadequate and modifications to the blades were made. The four inner scraper blades on each of the rake arms were lengthened and the width was increased.

After the implementation and testing of the control philosophy, the supply of thickened slurry to the bottom cone was addressed. In order to supply the underflow pumps with sufficient material without putting the rake under unnecessary strain, a variable speed drive was installed. The rake speed is automatically controlled and adjusted according to the underflow withdrawal rate.

\section{2 Results}

The trend lines obtained from the operations control system is shown in Figures 7 and 8. 


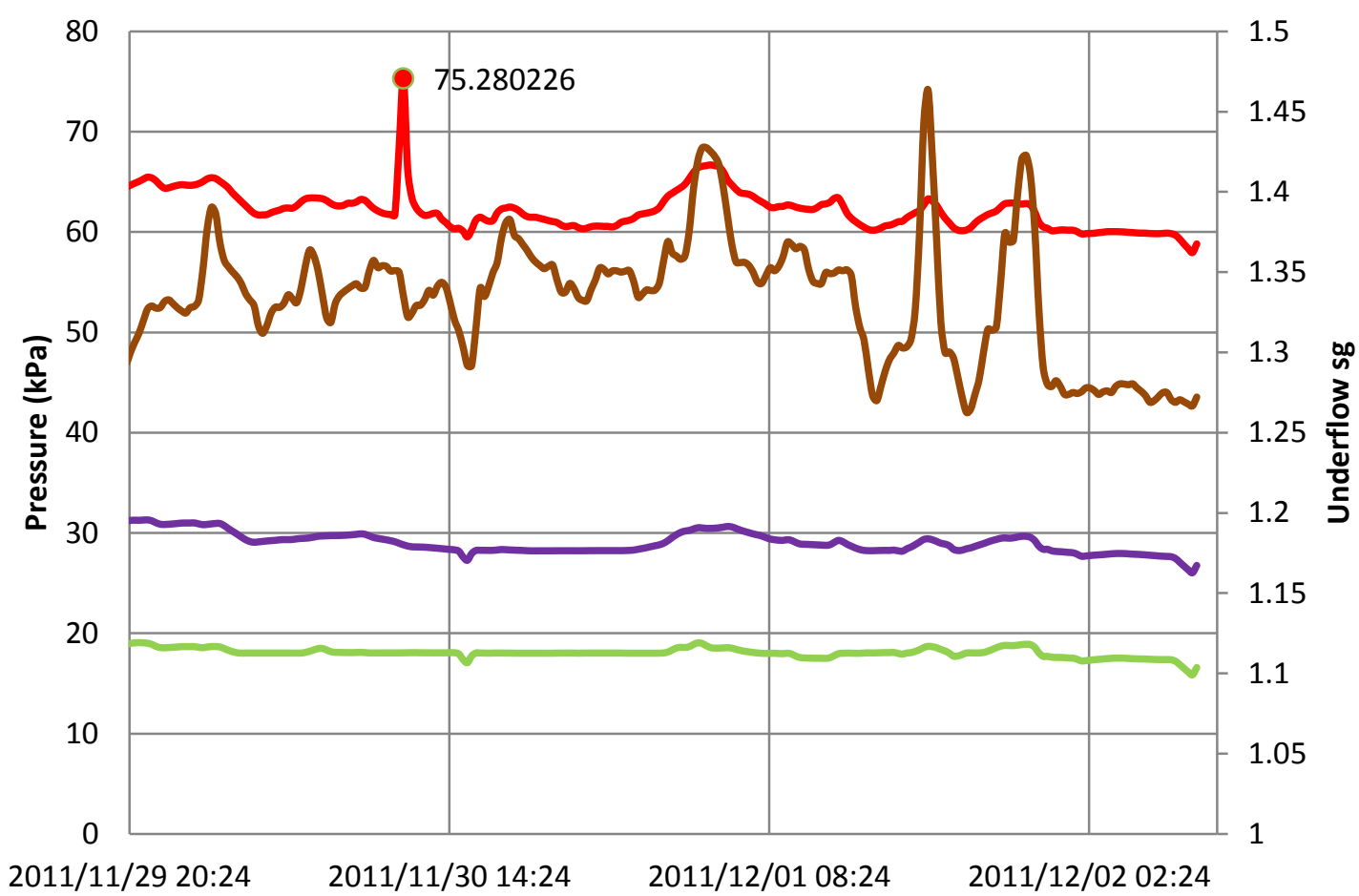

Pre Leach 1 Thickener Wall Bottom Pressure —Pre Leach 1 Thickener Cone Pressure

Pre Leach 1 Thickener Top Pressure

Pre Leach 1 Thickener Underflow Density

Figure 7 Trends of thickener wall top pressure, thickener wall bottom pressure, the thickener cone bottom pressure and the underflow sg

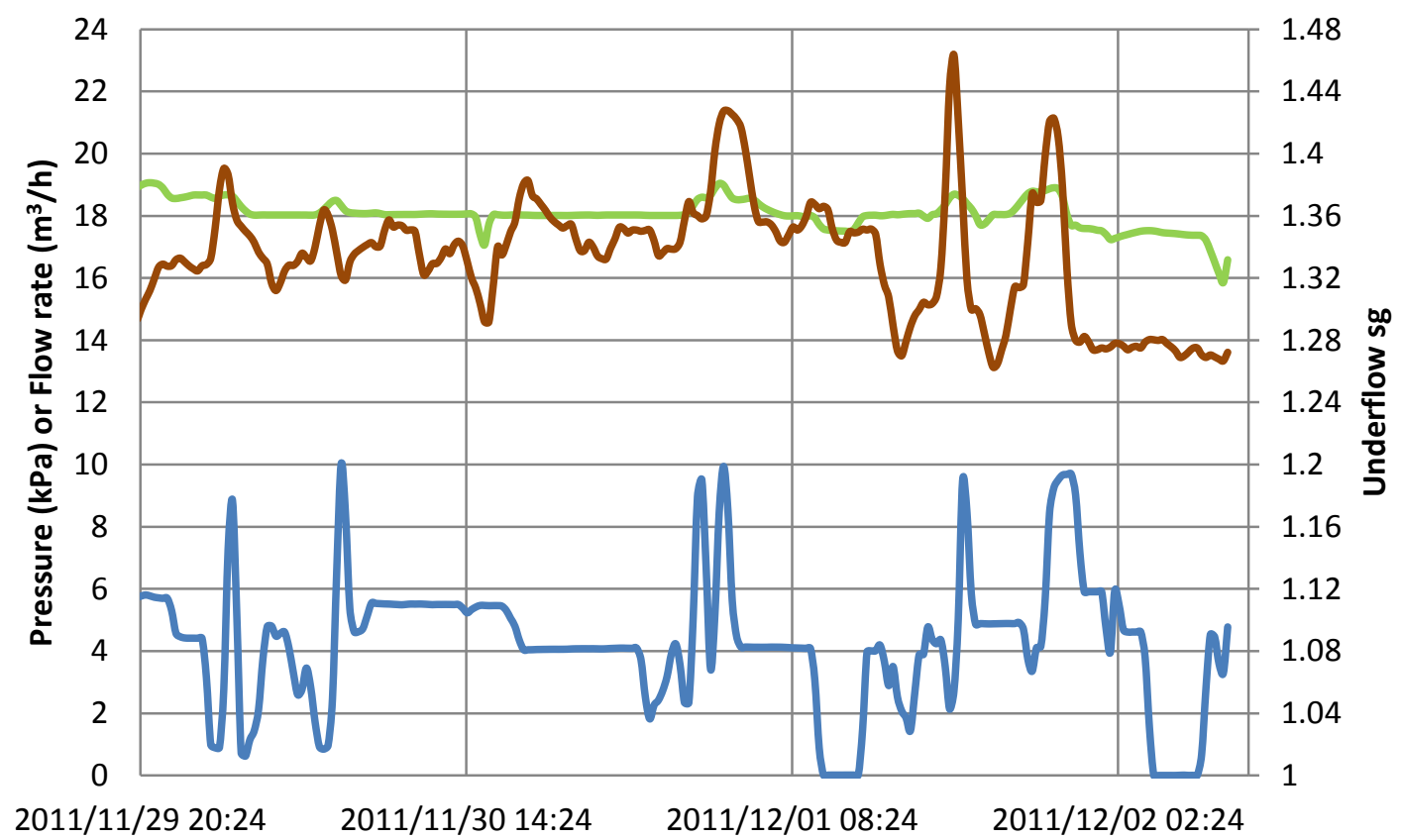

Flocc Feed to Pre-Leach1

Pre Leach 1 Thickener Top Pressure

Pre Leach 1 Thickener Underflow Density

Figure 8 The trends of the underflow sg, flocculant dosing rate and the side wall top pressure 
The pressure trends at different levels in the thickener, as shown in Figure 7, indicate the expected pressure profile from bottom to top. This pressure profile is utilised to control the thickener bed volume.

The maximum thickener cone pressure measured over the period was $75.28 \mathrm{kPa}$. This measurement occurred as a spike and was close to the maximum design specification of $76 \mathrm{kPa}$, as calculated from the design criteria, as indicated in Figure 5. During this occurrence, the wall pressures were not excessive, which leads to the conclusion that the bed density in the cone was very high and some sort of slumping occurred in the thickener. The pumped slurry density did not indicate the same spike, therefore it was concluded that some low density material reported to the cone at the same time and diluted the thickener underflow. This incident was an abnormal case of the normally more gradual correction of the difference between the cone density and the pumped underflow density.

The flocculant volumetric flow rate trend in Figure 8 indicates that the automated flocculant control is responding well to changes in the thickener.

The thickener wall top pressure will indicate sliming conditions. When the pressure rises to more than $18.3 \mathrm{kPa}$, an alarm is activated to indicate an over expanded bed and when the pressure rises to $18.5 \mathrm{kPa}$, the thickener is about to slime and the flocculant dosing is increased to maximum. The trend line for the pressure at this point, as given in Figure 8, indicates that the thickener bed volume is under control.

\section{3 Conclusion}

The addition of pickets and raking blade modifications increased the thickener capacity and can therefore be regarded as successful.

The measurement of the density profile in the thickener enabled the implementation of a reliable fully automated thickener control philosophy that does not utilise maintenance intensive instrumentation. This thickener control accommodated normal operational changes such as differences in flocculant make-up strength between batches that resulted in changed dosing volume and changes in feed mineralogy that resulted in changed flocculant requirement.

This improved information on the conditions in the thickener highlighted the areas where the thickener performance could be improved.

\section{$3 \quad$ ANDRITZ Delkor thickener operation and changes}

\section{1 Operational challenges}

The ANDRITZ Delkor thickeners have proved to be capable of thickening the Stage 2 tonnages. All ANDRITZ Delkor thickeners gave similar challenges; the feedwells were very turbulent at the feed slurry entry. Figure 9 shows typical feedwell entry turbulence and an overflowing feedwell. The feed distribution arrangement resulted in solids settling on the feedwell discharge plate. The feedwell was prone to blocking. Typical behaviour when the feedwell is filled with solids is shown in Figure 10. 


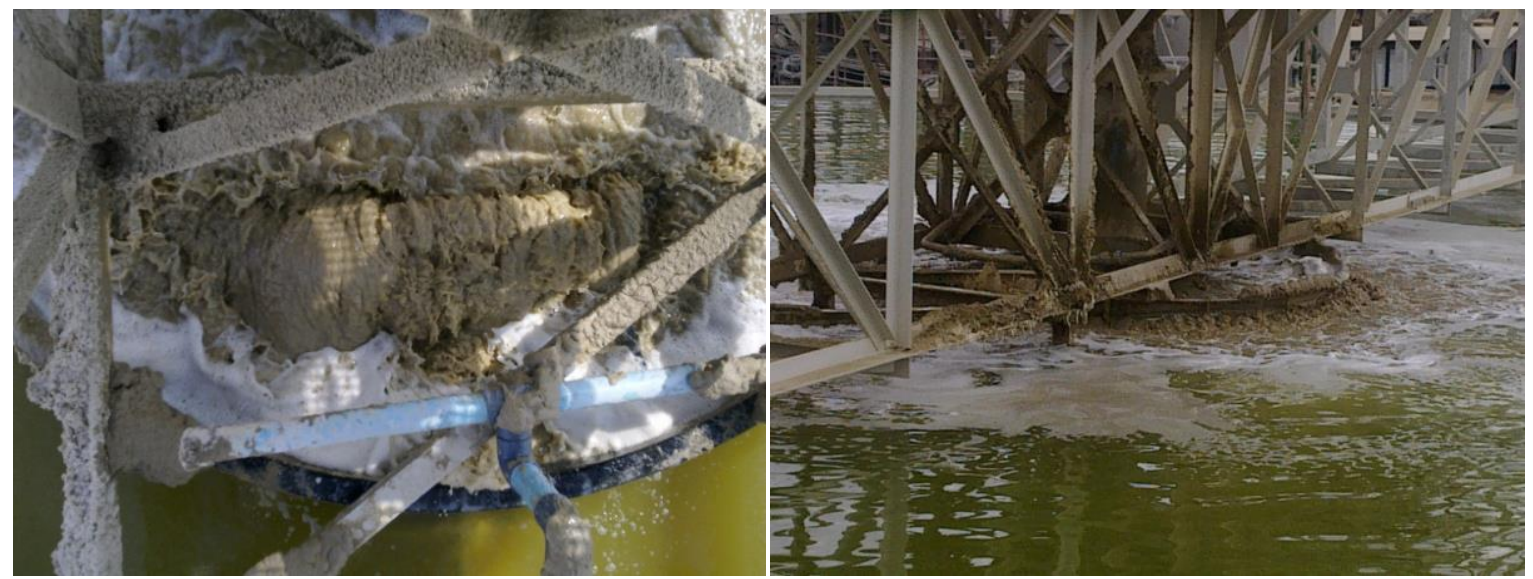

Figure 9 Turbulence in the feedwell at the point of entry is shown on the left. The feedwell overflowing is shown on the right

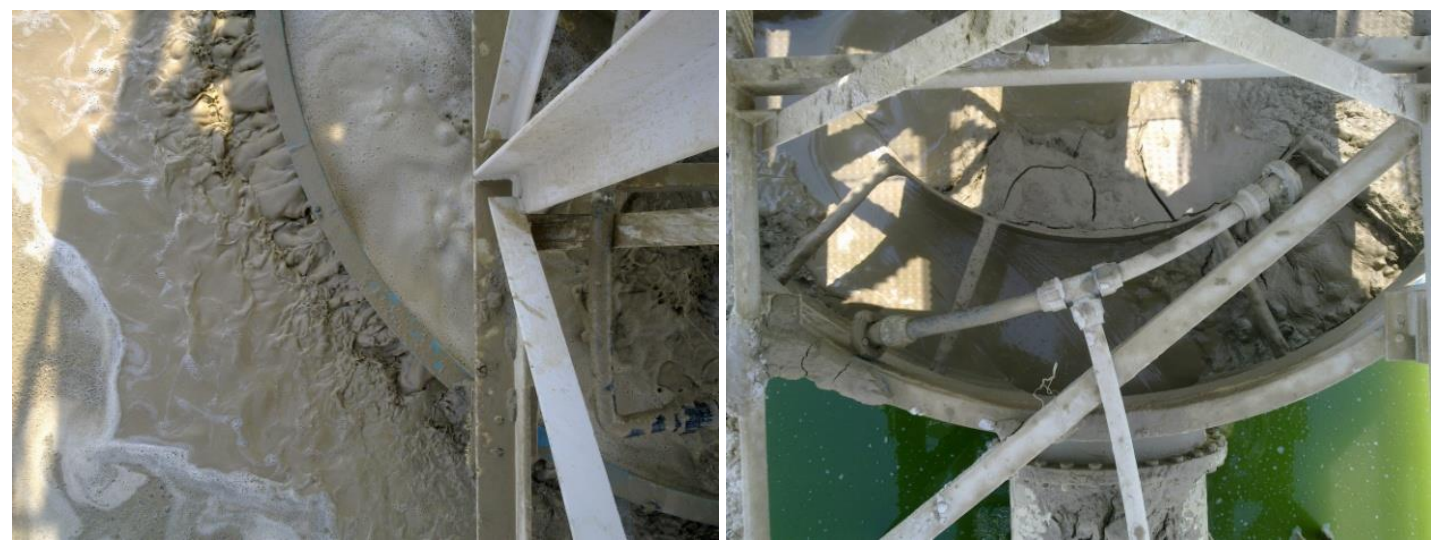

Figure 10 Closer view of the overflowing feedwell on the left. The feedwell filled with solids. The solids were exposed after the thickener level was lowered

The blocking of the feedwell eventually caused the feedwell discharge plate to shear from the mountings and fall onto the rake. Figure 11 shows a typical feedwell failure.
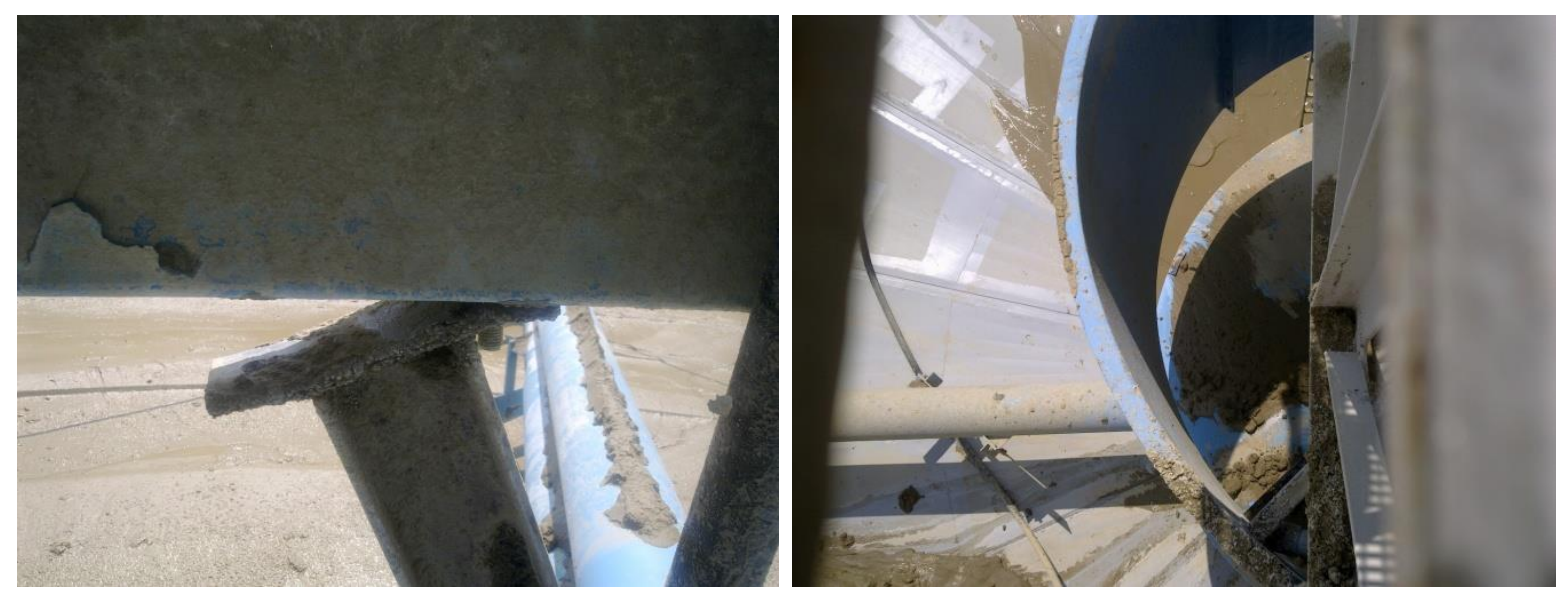

Figure 11 Typical mechanical failure of the feedwell

The rake drive frame became distorted when the rake was fully lifted and the rake torque was high. Typical drive frame failure is shown in Figure 12. 

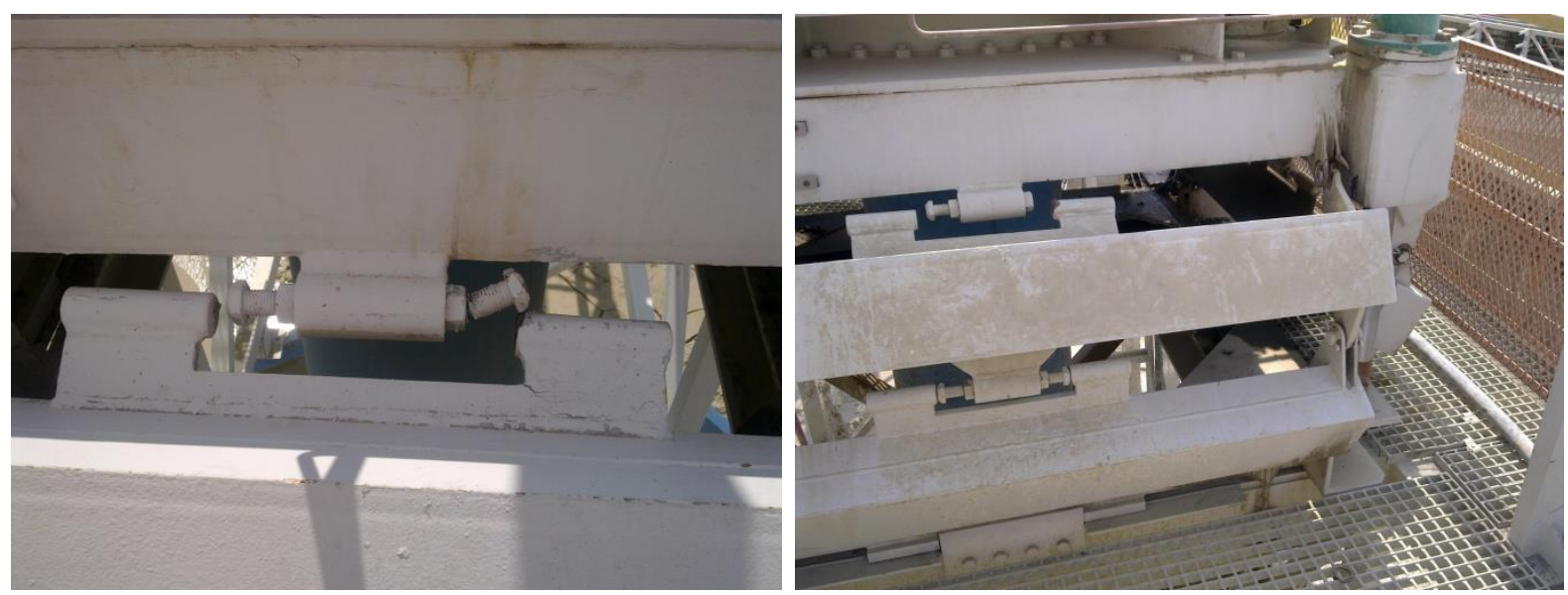

Figure 12 Distortion and failure of the drive head

\section{2 Mitigation of the challenges}

These problems were discussed with ANDRITZ Delkor and it was agreed that the rake drive frames would be upgraded to be able to withstand high torque conditions in the fully raised position. The design, fabrication and delivery were done under guarantee and the installation of the drive frame was done inhouse under ANDRITZ Delkor supervision.

The feedwell design was changed to tangentially feed, 60 seconds retention time and a conical discharge cone; in line with LHM specification. Figure 13 shows the retrofitting of the feedwell and the feedwell in operation. Figure 14 shows an installed new design drive frame. These modifications were implemented in the latter part of 2011. Each thickener was taken offline for a total of six to eight days for completion of the work. The first two to three days was required to drain and wash thickener. After the modifications, the slurry flow in the feedwell was less turbulent. The flocculation of the feed was satisfactory and the flocculant consumption decreased marginally. No failures or operational challenges were experienced up to the time of writing this paper.

LHM is satisfied that the vendor approached the challenges in a professional manner and supplied good after sales support for their equipment.
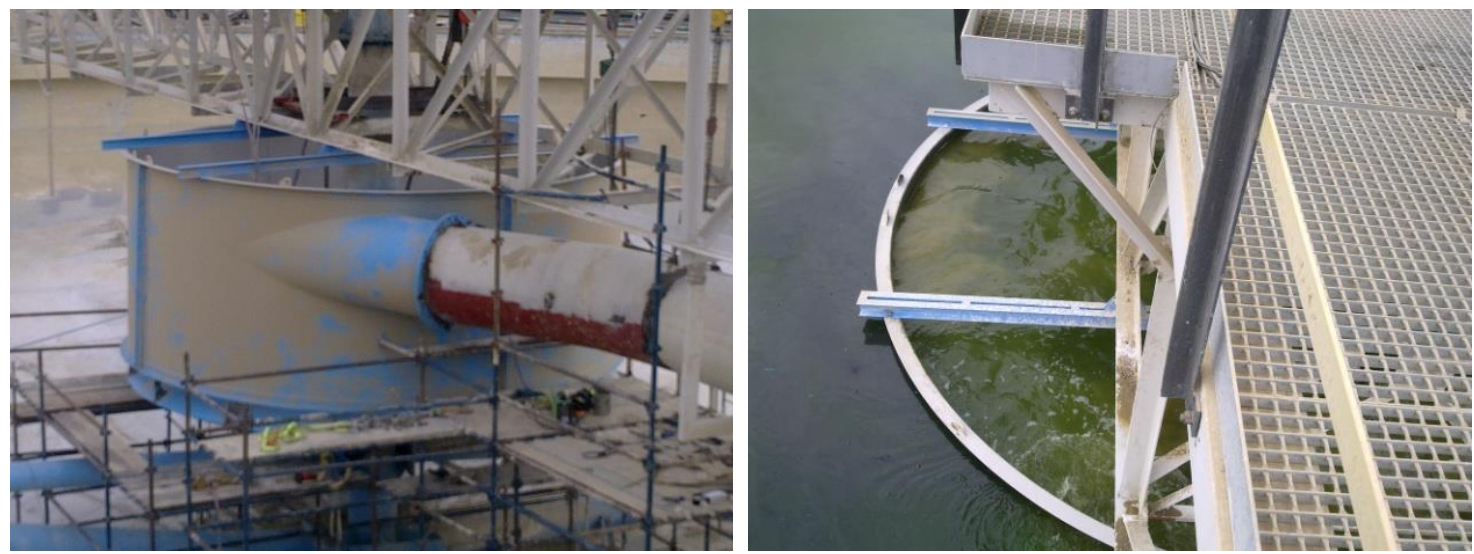

Figure 13 The feedwell retrofit and the feedwell in operation 


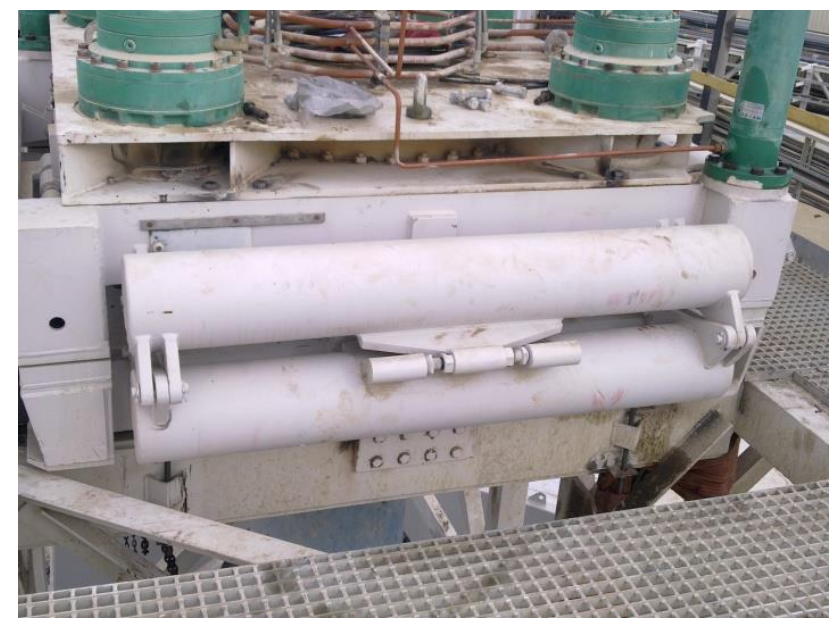

Figure 14 The installed new drive frame

\section{$4 \quad$ Roymec Technologies (Pty) Ltd thickeners}

The Roymec thickeners were commissioned in the latter part of 2011. During the commissioning of the thickeners, a slug of high density slurry reported to these thickeners. The feedwells filled with this slurry and blocked it partially. LHM washed the feedwells out, but the feedwells promptly filled with slurry again. LHM is in discussions with the vendor to solve this feedwell problem, but LHM still regard this as a ramp-up problem that will diminish when full Stage 3 production volumes are processed.

The thickener header tanks did not manage to accommodate process conditions well and did not draw dilution water in, and mixed the dilution water with the slurry when the feed density to the header tank reached a value close to $1.43 \mathrm{gcm}^{-3}$. The CCD circuit is normally operated at an underflow density range of $1.40-1.43 \mathrm{gcm}^{-3}$.

Discussions were held with the vendor and some changes to the stirrer and mixing arrangement in the header tank were made to mitigate this problem. These changes resulted in some improvement, but the problem still occurred from time to time. Measurement of the thickener and header tank levels showed that the level differences could contribute to the problem.

\section{1 Conclusion}

LHM decided to change the process set points of the preceding thickeners and limit the feed density to the header tank to $1.35 \mathrm{gcm}^{-3}$ density slurry. These set points will be reviewed when the full Stage 3 capacity is reached. When the header tank functions correctly and the diluted feed to the thickener is the correct density, the volumetric flow to the thickener feedwell will increase and the flow dynamics in the feedwell will improve. The risk of solids build-up in the feedwell will be mitigated. As an additional precaution, the thickener will be put into operation without flocculant addition. Flocculant will only be dosed after five minutes, once the flow dynamics in the feedwell has stabilised.

Operational procedures to recover the header tank with minimal process disruption have been developed. The thickeners have been performing well in terms of the underflow and have produced the specified underflow density.

\section{$5 \quad$ Paste system}

The LHM paste system consists of a $12 \mathrm{~m}$ UltraSep 2000 High Performance Thickener supplied by MPE; feed and underflow systems designed by P\&C and a TSF designed by Metago Environmental Engineers. Metago Environmental Engineers has been incorporated in SLR Consulting. The TSF was designed to accept slurry with a density range from $1.50-1.6 \mathrm{gcm}^{-3}$. 
The UltraSep 2000 is a rakeless thickener. The commissioning of the UltraSep 2000 proved to be a major challenge. The underflow density was unpredictable and ranged from $1.38-1.55 \mathrm{gcm}^{-3}$ with the most common densities in the range $1.43-1.48 \mathrm{gcm}^{-3}$. The low density material reporting to the TSF filled the TSF quicker than planned. Under some calculated scenarios, the TSF life could decrease by almost a year should the deposition of low density material continue.

The water that reported to the TSF was more than planned for and additional measures had to be taken to pump the water back to the plant and prevent environmental contamination. The rate of TSF wall building had to be increased.

During commissioning the UltraSep 2000 internal cones deformed and sheared off the mountings. The thickener had to be repaired. MPE lifted and remounted the internals under guarantee. The deformation and failure is shown in Figures 15 and 16 respectively.

The vendor has made some design changes to the vibrators on the thickener cone and installed additional vibrators to mitigate the challenges. These changes were commissioned, but did not manage to increase the underflow to a consistent density within the STF design range.

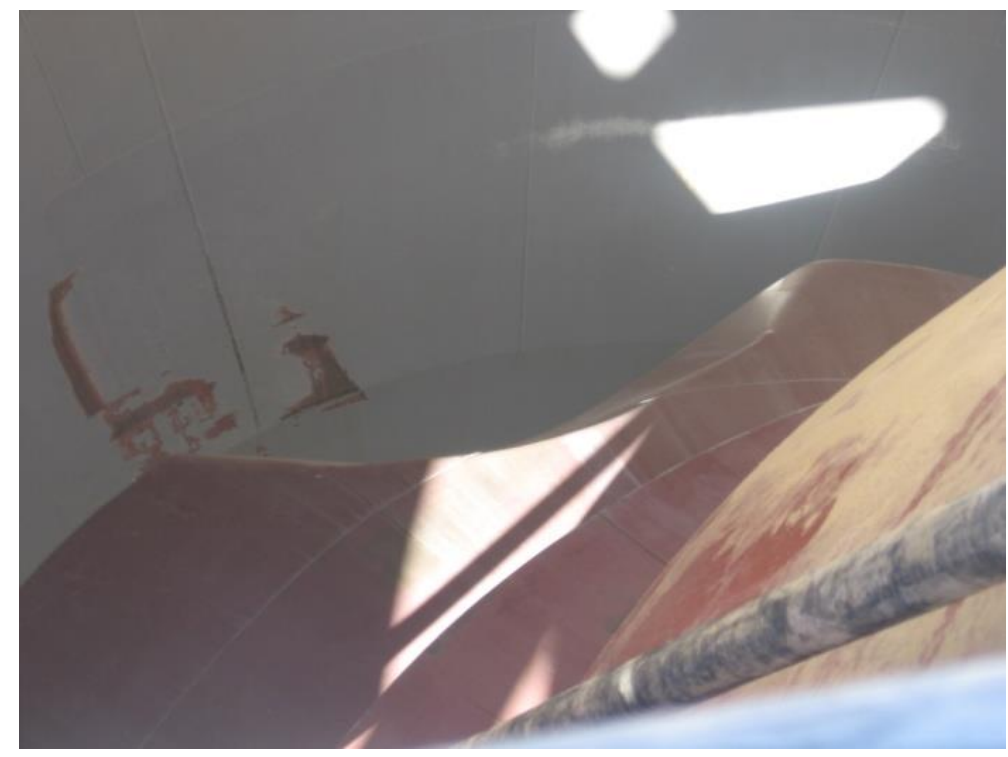

Figure 15 Deformation of the UItraSep 2000 internal cones

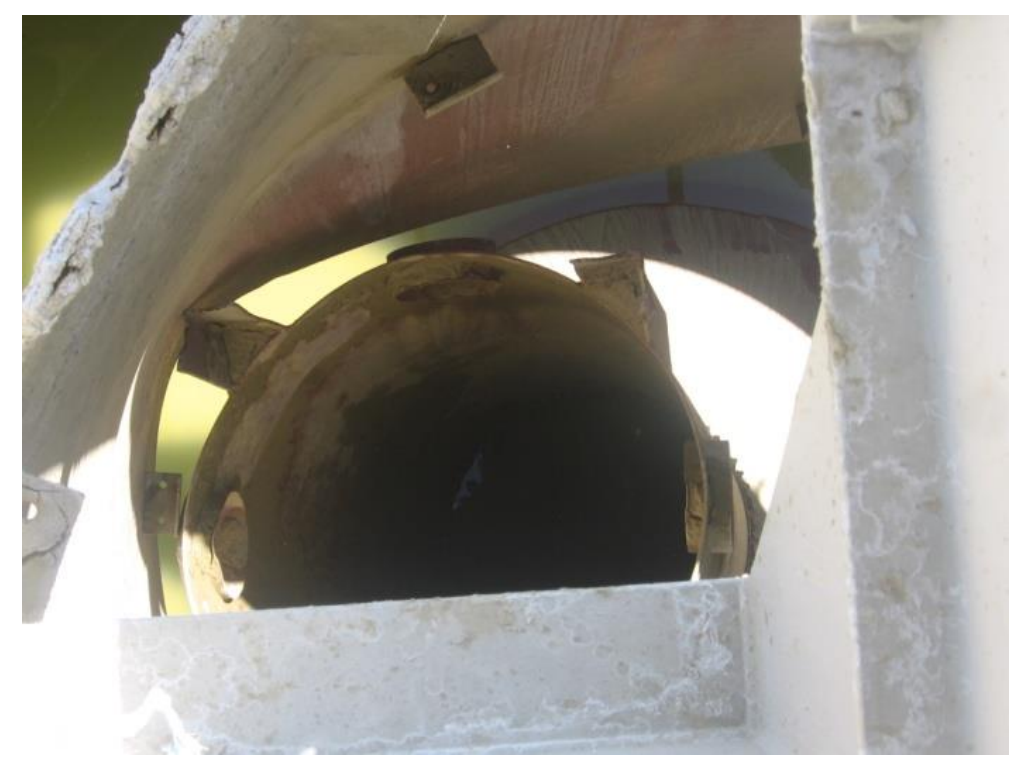

Figure 16 The UItraSep 2000 internals were sheared off the mountings 


\section{1 Conclusion}

LHM decided to install two Endress+Hauser viscometers: one at the in-plant tailings system feeding the UltraSep 2000 and one at the UltraSep 2000. The viscometers are enhanced Coriolis meters capable of accurate viscosity and density measurement.

The yield stress of LHM slurry increases rapidly at densities higher than $1.40 \mathrm{gcm}^{-3}$. The viscometer at the in-plant tailings would improve the control of the pump and pipeline feeding the UltraSep 2000. This system can then be operated at densities resulting in the design rheological properties. This would mitigate the risk of pipeline blockages while the solids transport out of the processing plant can be maximised.

It is envisaged that the viscometer at the UltraSep 2000 would enhance the control of the thickener feed and would provide information on the rheological properties of the slurry reporting to the TSF.

The viscometer at the thickener will do duty on the thickener overflow and the thickener underflow. The viscosity and density of the overflow is expected to give direct indication of flocculant over dosing and thickener sliming conditions respectively. By including the viscometer in the thickener underflow control, the quantity of low yield stress material reporting to the TSF can be minimised.

LHM also decided to test methods of shear thinning the thickener bed to mitigate the risk of damage to the thickener internals at high densities. The feed into the feedwell will also be changed in line with newer, proven feed arrangements. 
